\title{
Monitoring fish in California Channel Islands marine protected areas with a remotely operated vehicle: the first five years
}

\author{
Konstantin A. Karpov ${ }^{1, *}$, Mary Bergen ${ }^{2}$, John J. Geibel ${ }^{3}$ \\ ${ }^{1}$ Karpov Marine Biological Research, Fort Bragg, California 95437, USA \\ ${ }^{2}$ Rancho Dos Rios, Ojai, California 93023, USA \\ ${ }^{3}$ California Department of Fish and Game, Belmont, California 95402, USA
}

\begin{abstract}
In 2003, California established a network of marine protected areas (MPAs) in the northern Channel Islands, offshore of Santa Barbara. In this paper, we analyzed data from remotely operated vehicle (ROV) surveys of fish on deep-water (31-100 m) hard-bottom substrates. We tested the null hypothesis that there is no significant difference in density of target species inside and outside MPAs and also evaluated changes in density over time. The confounding variables water depth and substrate type were controlled by equalizing sampling effort. For the analysis, we used ANOVA with the factors treatment (MPA vs. fished), location of site pair (San Miguel Island, north Santa Rosa Island and southwest Santa Rosa Island) and time (2005 to 2008). Because the main factors were crossed, interactions between factors were used to indicate possible significant effects. Multiple $t$-tests were used to test for significant treatment effects depending on the type of interaction. Most significant interactions were associated with location. There was only one significant interaction between treatment and time. Using multiple comparison tests instead of averages from the main factors in the ANOVA exposed the underlying variability. No species was consistently more abundant in MPAs than in fished sites at all locations. This study evaluates the first $5 \mathrm{yr}$ after implementation of the MPAs. With additional time, we expect densities to change and the full dimensions of protection should become evident.
\end{abstract}

KEY WORDS: Fish abundance $\cdot$ Hard bottom $\cdot$ Marine protected area $\cdot$ Remotely operated vehicle . Sample design $\cdot$ ANOVA

\section{INTRODUCTION}

It is well established that, on average, population density is higher in marine protected areas (MPAs) than in nearby reference areas. In a review of 89 studies, Halpern (2003) found that the average density in MPAs was 1.9 times the density in reference areas. Lester et al. (2009) measured a ratio of 2.66 $(\mathrm{n}=118)$. However, although average density was higher, the results were highly variable. In Halpern (2003), density was not significantly different or was lower in 30 and $7 \%$ of the MPAs, respectively. In
Lester et al. (2009), ratios varied from negative to more than 10 .

Given this variability, managers and scientists cannot assume that protecting an area will produce results. MPAs must be monitored to measure responses relative to goals and objectives. In addition, factors other than protection need to be studied to elucidate variability. Confounding factors can obscure the response to protection (Huntington et al. 2010).

When a network of MPAs was developed in the northern Channel Islands, offshore of Santa Barbara, 
California, ecological factors known to affect marine populations were incorporated into the design (Airamé et al. 2003). Based on oceanographic and biological data, the region was divided into 3 biogeographical regions. Habitats were defined in terms of sediment type, water depth and dominant plant types. Alternate networks were then configured to have 1 to 4 reserves, comprising $30-50 \%$ of the area, in each bioregion. MPAs were chosen to include all habitats in the smallest possible area. The California Fish and Game Commission then selected a network, which was implemented in 2003.

Biological monitoring for the network was designed to measure changes in populations, ecosystem structure, habitats and spillover (www.dfg.ca.gov/ marine/channel_islands/). Monitoring activities were prioritized according to target habitats defined during the design of the network. The highest priority was given to shallow $(0-30 \mathrm{~m})$ and deep $(31-100 \mathrm{~m})$ hard-bottom habitats.

Monitoring protocols for SCUBA divers were well developed and have been frequently used in evaluating MPAs (Edgar \& Barrett 1997, Abesamis \& Russ 2005, Tetreault \& Ambrose 2007). In the northern Channel Islands, the Partnership for Interdisciplinary Studies of Coastal Oceans (PISCO) began monitoring shallow water sites in 1999. Their protocols were refined for monitoring the MPAs and their sites incorporated into the MPA monitoring program (Hamilton et al. 2010, also see www.piscoweb.org/research/ kelp-forests).

Protocols for monitoring in deeper water, however, needed to be developed. Submarines (e.g. Yoklavich et al. 2000, Love et al. 2009) and remotely operated vehicles (ROVs) (e.g. Barry \& Baxter 1993, Parry et al. 2003, Trenkel et al. 2004) have been used to survey benthic invertebrate and fish populations. However, to the best of our knowledge, ROVs have not been used to study deep-water fish populations in MPAs. To allow for comparison of results from shallow and deep water, our survey protocols were specifically designed to be similar to those used by SCUBA divers. Both the sample design and survey protocols were crafted to allow for robust statistical analysis of the data (Karpov et al. 2006, 2010).

In this paper we present the first results of the ROV surveys conducted by the California Department of Fish and Game (CDFG) of fish on deep-water, hardbottom sites inside and outside MPAs in the northern Channel Islands. Specifically, we test the null hypothesis that there is no significant difference in density of target species inside and outside of MPAs. We also evaluate changes in density of fish over time that might be attributed to an MPA effect. The confounding variables water depth, substrate type and location are controlled as much as possible in our analysis.

\section{MATERIALS AND METHODS}

\section{Sampling design}

The framework of the monitoring for the Channel Island MPAs was developed in a workshop including representatives from the scientific community, recreational and commercial fisheries, conservation groups, governmental agencies and the public (www.dfg.ca.gov/marine/channel_islands/). The objective of the biological monitoring was to determine: (1) changes in abundance, size, biomass and spawning biomass of species; (2) species composition as it relates to ecosystem function; (3) habitat changes; (4) amount of spillover; and (5) changes in catch per unit effort and total catch. Monitoring activities were separated into 4 general categories: intertidal, shallow subtidal, deep subtidal, and seabirds and mammals. In general, it was expected that an MPA's level of effectiveness would be determined by comparing responses of focal species within and outside MPAs. Focal species were selected to represent a range of life histories and expected responses.

The objective of the ROV surveys was to measure changes in density of deep-water fish on hardbottom substrates between 20 and $100 \mathrm{~m}$ at a single site within an MPA and a single site outside the MPA. When possible, the site within a MPA was located adjacent to shallow water, hard bottom sites being surveyed with SCUBA by PISCO (Hamilton et al. 2010). Fished sampling sites were located near, but not immediately adjacent to MPAs to avoid spillover effects. Where possible, adjacent sites were chosen to be similar in terms of depth and substrate type. Ten sites (6 MPAs and 4 fished areas) were selected for monitoring and intensively sampled from 2005 through 2008 (Fig. 1).

Each site was delimited by 2 to 5 contiguous rectangles, each $500 \mathrm{~m}$ wide, positioned using sonar maps and exploratory surveys (Fig. 2). Rectangles were offset laterally and lengthened offshore as needed to capture the most available hard substrate within the targeted depth range. After each annual survey, areas within each rectangle having $>70 \%$ soft substrate were excluded from future sampling. 


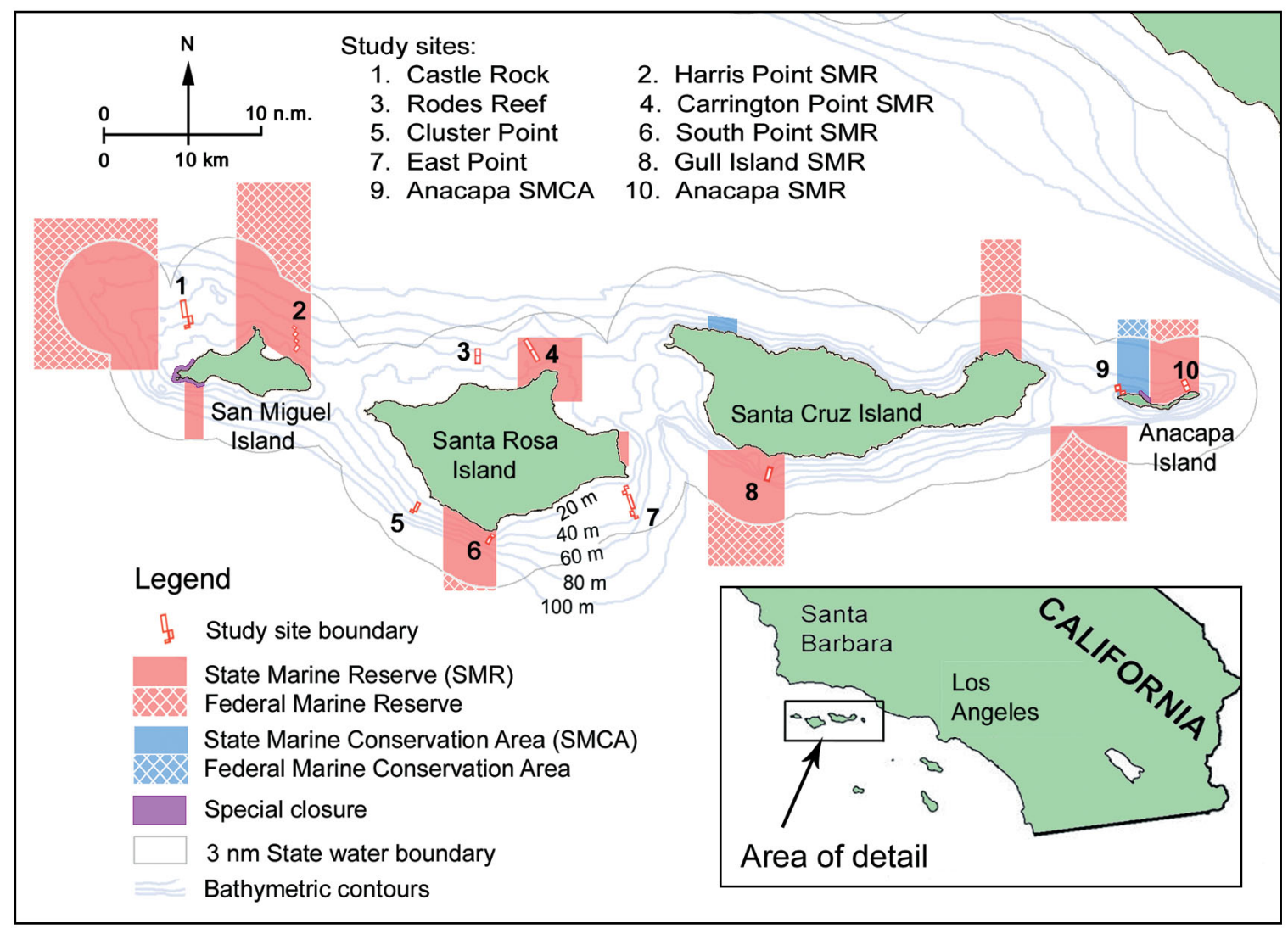

Fig. 1. Location of 10 study areas within and outside marine protected areas (MPAs) sampled quantitatively for deep-water finfish from 2005 through 2008. Only Sites 1 through 8 were used in our analysis

\section{Data collection}

Target lines for swath sampling with the ROV were $500 \mathrm{~m}$ long, spanning the fixed width of the rectangles (Fig. 2). Each year the lines were randomly placed a minimum of $20 \mathrm{~m}$ apart. Because the amount of target substrate varied among rectangles and sites, the number of lines per rectangle at each site was weighted inversely to the amount of hard substrate.

The ROV was used to videotape a swath of known width and length along the target lines. The ROV was a Deep Ocean Engineering model HD 2+2 equipped with forward and down-facing cameras and a Tritech $\operatorname{Ltd}^{\circledR}$ model PA 500/6 acoustic ranging sonar. The sonar was used to measure the distance to the substrate at the center of the video image. The location of the ROV was determined with a Trackpoint $\mathrm{II}^{\circledR}$ acoustic/transponder linked to a shipboard Garmin ${ }^{\circledR}$ Wide Area Augmentation System dGPS. The distance to the substrate and the navigational data were used to compute the width and length, respectively, of transects (Karpov et al. 2006).
On the ship, target lines, positions of the ROV and the ship, water depth, and distance from the ROV to the substrate were displayed on video monitors used for navigation. The ROV pilot maintained a straight forward course $\left( \pm 5^{\circ}\right)$ within $10 \mathrm{~m}$ of the target line while the ship's captain maintained position relative to the ROV. The ROV was flown at a relatively constant velocity of 0.5 to $0.75 \mathrm{~m} \mathrm{~s}^{-1}$. The camera faced forward at a slant angle of $20^{\circ}$ approximately $2 \mathrm{~m}$ from the targeted substrate. This protocol was crucial to maintaining precision and accuracy of the track line (Karpov et al. 2006).

The original design called for oversampling each site to produce a minimum of $15050-\mathrm{m}^{2}$ transects at each site every year (Karpov et al. 2010). Oversampling was needed to allow for sample loss when the ROV was 'offline', too far from the substrate, or in unsuitable habitat. During post-processing, all fish larger than $11 \mathrm{~cm}$ were enumerated and substrate was classified in video records with forward visibility that exceeded $4 \mathrm{~m}$. Occasionally suspended sediments, particulates and/or plankton reduced visibility to $\leq 4 \mathrm{~m}$; this video was rejected from further analysis. 


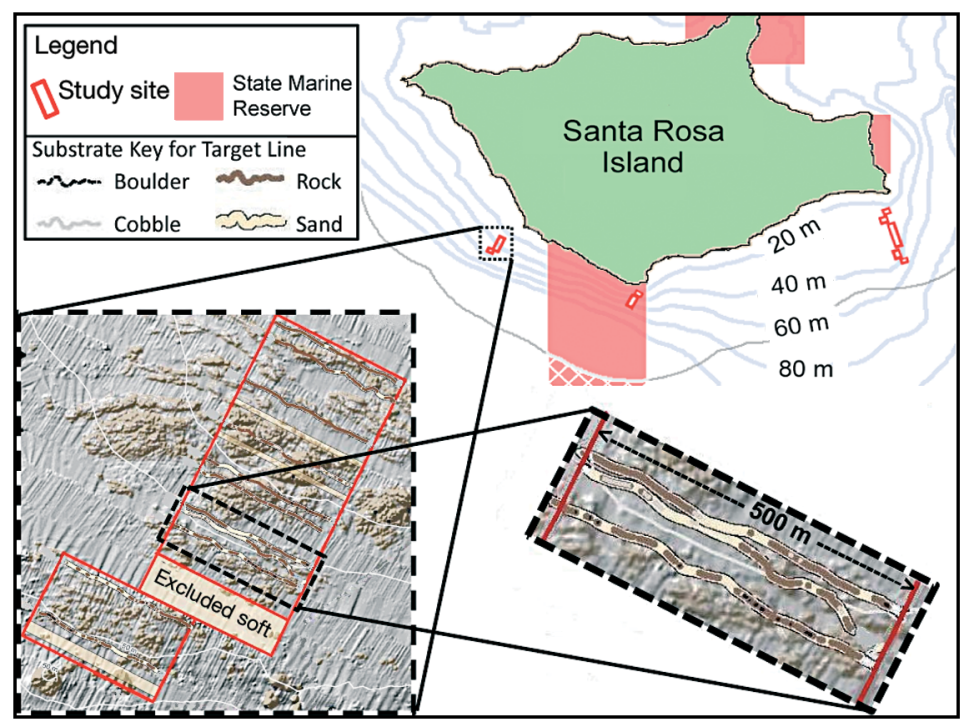

Fig. 2. Detailed view of Cluster Point study site, showing 2 rectangular boundaries and the 11 randomly placed target lines sampled in 2007 . Close-up of 3 target lines shows substrate types as interpreted from the remotely operated vehicle (ROV) video

Fish, identified to discernible taxa (e.g. species, species complex, family or unidentified), were counted with the aid of a transparent film overlay of the top half of the video screen monitor. Two converging guidelines on the transparency approximated the vanishing perspective of the strip transect based on the camera tilt angle relative to the forward plane of view. Only fish that were at least halfway within the guidelines and within $4 \mathrm{~m}$ of the camera were counted. Distances from the camera were based on the sonar range value on the screen.

Substrate was classified as rock, boulder, cobble or sand (Fig. 2) using categories simplified from Greene et al. (1999). A substrate layer was considered to be continuous until there was a break of $2 \mathrm{~m}$ or the substrate comprised less than $20 \%$ of the total substrate for a distance of at least $3 \mathrm{~m}$. Substrates were then combined into 3 habitat types: (1) hard only (rock and/or boulder), (2) mixed (rock and/or boulder with soft) and (3) soft only (cobble and sand).

Although our target habitat was 'hard bottom', we included rock-sand interface and areas of mixed habitat by using navigational data and habitat classifications to aggregate two $25-\mathrm{m}^{2}$ components (approximately $2.5 \times 10 \mathrm{~m}$ ) of the video record into $50 \mathrm{~m}^{2}$ strip transects with substrates classified as hard or mixed. Components with $>50 \%$ soft-only substrate were discarded. Using these protocols, large patches of soft-only substrate $(>5 \mathrm{~m})$ were avoided while producing transects with $\leq 50 \%$ soft-only substrate.

\section{Data analysis}

The 12 most common taxa ${ }^{1}$ were selected for analysis. As one measure of MPA effect, density response ratios (ln [MPA density/ fished density]) were calculated for all species combined and for each of the 12 finfish (Hedges et al. 1999). If density was higher in MPAs, the ratio was $>0$.

ANOVA was used to test the null hypothesis that there is no significant difference in density of target species inside and outside of MPAs for each of the 12 species. To isolate the effect of the MPAs, confounding factors, particularly depth, target substrate and biogeography, needed to be controlled. In addition, because density was expected to increase in MPAs over time, time was a factor in the analysis.

To control for biogeography, for our analysis we selected 4 site pairs (an MPA with a nearby fished site) located in 2 of the 3 biogeograhic regions in the Channel Islands (Airamé et al. 2003 and references therein). Three pairs were in the Oregonian Province: (1) Harris Point State Marine Reserve (SMR) and Castle Rock on northern San Miguel Island; (2) Carrington Point SMR and Rodes Reef on northern Santa Rosa Island; and (3) South Point SMR and Cluster Point on southwest Santa Rosa Island. The fourth pair, Gull Island SMR on southwestern Santa Cruz Island and East Point on southeast Santa Rosa Island, was in the Transition Zone between the cold Oregonian and the warmer Californian Province (Fig. 1). The 4 fished controls were located 1.5 to $7 \mathrm{~km}$ from the boundary of their respective MPAs. The 2 MPAs on Anacapa Island were not used because they did not have nearby control sites.

Before proceeding with the analysis, site pairs were evaluated for comparability of sampling effort across depth and substrate type. Mean depth and percent soft-only substrate were computed for each site. In addition, the number of transects in $10 \mathrm{~m}$ bins for depth and $10 \%$ bins for substrate type was plotted for each site pair. If sampling effort did not overlap by at least $60 \%$, the site pair was eliminated from the analysis.

\footnotetext{
1 The 12 taxa include the sub-genus Sebastomus and 11 fish identified to species. Because only one taxon is not specifically identified, the term 'species' is used henceforth in place of taxa.
} 
A total of $781950-\mathrm{m}^{2}$ transects were collected at the 8 sites, ranging from 150 to 367 transects per site in a given year. Because there were excess transects, it was possible to further equalize sample effort by depth and substrate type for a more balanced analysis. Equalizing sampling effort was needed to avoid confounding as much as possible.

A 2-step process was used to select transects to retain for analysis. In the first step, for each site pair, the smallest sample size in each depth bin was selected as the common denominator. Excess transects were randomly selected and discarded. Bins with $<5$ transects for either site were discarded from the analysis. Then, for each site pair, the number of transects in each depth bin in each year was displayed in a table. A provisional number was selected as the sample size for each year (e.g. 100 transects). Transects were randomly selected and removed so that the sample size was relatively equal within each depth bin/year combination. The final number of transects for each year was chosen by iteration. In the end, the sample size was identical for each site pair for each depth bin and for each year, but not equal for each depth bin within each year among site pairs.

Even though sampling effort was equalized, we expected the density of species to vary with depth. To elucidate the relationship between density and depth, the average density of each species within $10 \mathrm{~m}$ depth bins was analyzed using 1-way ANOVA (PROC GLM in SAS).

Although balancing sampling effort controlled for the effects of depth and target substrate, density was expected to differ between site pairs because of the biogeographic gradient. In addition, density might change significantly over time, particularly in the MPAs. We therefore used 3-way ANOVA with factors treatment (MPA vs. fished), location (San Miguel Island, northern Santa Rosa Island and southwestern Santa Rosa Island) and time (2005-2008). Treatment was a fixed factor in the ANOVA model because a site was either protected or fished. Location and time were random factors because there was no predictable effect of either factor on density (Underwood 1997). However, because there was a single site pair (MPA and fished site) at each location and each site was sampled each year, the factors location and year were crossed (i.e. orthogonal), preventing a direct test for the main effect of treatment.

We therefore used the 3-way ANOVA to indicate possible significant effects of treatment, location and/or time, i.e. if the interaction term was significant, it suggested that one or more factors were significantly affecting density. Depending on the type of interaction, the factors were separated and multiple comparison tests were used to test for significant treatment effects. If the 3 -way interaction (treatment $\times$ year $\times$ location) was significant $(\mathrm{p} \leq 0.05)$, $t$-tests (MPA vs. fished) were performed for each location each year. If the treatment $\times$ year interaction was significant, $t$-tests were performed for each year (locations combined), and if the treatment $\times$ location interaction was significant, $t$-tests were performed for each location (years combined). If both 2-way and 3 -way interactions were significant, only the test for the 3-way interaction was performed.

All densities were transformed prior to analysis using the method of Pearse \& Hines (1987) (transformed density $=\ln [$ density +1$]$ ). Because the Bonferroni adjustment ( $p=0.05 /$ number of tests) for multiple testing (Mason et al. 1989) was, in our estimation, overly conservative, we used $\mathrm{p} \leq 0.05$ as the criterion for statistical significance. We provide the adjusted $\mathrm{p}$-value in table and figure captions for readers who wish to use the Bonferroni adjustment.

\section{RESULTS}

In the source data, the amount of target substrate ranged from $35 \%$ at Gull Island SMR to $92 \%$ at Castle Rock (Table 1). The exclusion of segments with $>50 \%$ soft-only substrate produced transects with 86 to $99 \%$ target substrate. Exclusion of the segments did not appreciably change the mean depth of the samples.

The distribution of sampling effort for percent targeted substrate was similar in all 4 site pairs (Fig. 3a). Most transects had 91 to $100 \%$ targeted substrate. Overlap of sampling effort within site pairs ranged from 68 to $94 \%$. The distribution of sampling effort for depth differed within and among site pairs. Most of the samples at Carrington Point SMR, Rodes Reef and East Point were taken in less than $44 \mathrm{~m}$ of water. At Gull Island SMR and Harris Point SMR, no samples were taken in less than $25 \mathrm{~m}$ of water. Overlap of sampling effort by depth ranged from 66 to $81 \%$ for 3 site pairs. For Gull Island SMR and East Point, however, overlap was only $11 \%$. Substrate relief also differed between Gull Island SMR and East Point (Table 1). East Point had low $(<2 \mathrm{~m})$, medium (2 to $<3 \mathrm{~m})$ and high $(\geq 3 \mathrm{~m})$ relief substrate. Gull Island SMR had medium and high relief, but little low relief substrate. Substrate relief was similar within each of the other 3 site pairs. Because there was insufficient overlap for depth, the Gull Island SMR/East Point pair was excluded from the analysis. 
Table 1. Mean depth $( \pm 95 \% \mathrm{CI})$, percent targeted substrate and relief (L: low, $<2 \mathrm{~m}_{i} \mathrm{M}$ : medium, 2 to $<3 \mathrm{~m} ; \mathrm{H}$ : high, $\left.\geq 3 \mathrm{~m}\right)$ for the fished and state marine reserve (SMR) study sites. Values for depth and percent targeted substrate are given for the source data; all transects and the subset balanced by depth

\begin{tabular}{|c|c|c|c|c|c|c|c|}
\hline \multirow{2}{*}{$\begin{array}{l}\text { Island location } \\
\text { Study site }\end{array}$} & \multicolumn{2}{|c|}{ Sampled area ${ }^{\mathrm{a}}$} & \multicolumn{2}{|c|}{ All transects ${ }^{b}$} & \multicolumn{2}{|c|}{ Balanced subset ${ }^{\mathrm{b}, \mathrm{c}}$} & \multirow{2}{*}{$\begin{array}{l}\text { Substrate } \\
\text { relief }\end{array}$} \\
\hline & $\begin{array}{l}\text { Depth } \\
\text { (m) }\end{array}$ & $\begin{array}{c}\text { Targeted } \\
\text { substrate }(\%)\end{array}$ & $\begin{array}{l}\text { Depth } \\
\text { (m) }\end{array}$ & $\begin{array}{c}\text { Targeted } \\
\text { substrate }(\%)\end{array}$ & $\begin{array}{l}\text { Depth } \\
\text { (m) }\end{array}$ & $\begin{array}{c}\text { Targeted } \\
\text { substrate }(\%)\end{array}$ & \\
\hline \multicolumn{8}{|l|}{ San Miguel Island (north) } \\
\hline 1. Castle Rock & $45.4 \pm 0.3$ & 92 & $45.5 \pm 0.6$ & 99 & $41.8 \pm 0.8$ & 99 & $\mathrm{M}, \mathrm{H}$ \\
\hline 2. Harris Point SMR & $42.1 \pm 0.2$ & 58 & $42.3 \pm 0.5$ & 94 & $41.4 \pm 0.7$ & 94 & $\mathrm{M}, \mathrm{H}$ \\
\hline \multicolumn{8}{|l|}{ Santa Rosa Island (north) } \\
\hline 3. Rodes Reef & $29.0 \pm 0.2$ & 67 & $27.4 \pm 0.3$ & 94 & $29.3 \pm 0.5$ & 92 & $\mathrm{~L}, \mathrm{M}$ \\
\hline 4. Carrington Point SMR & $30.3 \pm 0.2$ & 56 & $29.7 \pm 0.3$ & 94 & $29.4 \pm 0.5$ & 94 & $\mathrm{~L}, \mathrm{M}$ \\
\hline \multicolumn{8}{|l|}{ Santa Rosa Island (southwest) } \\
\hline 5. Cluster Point & $37.2 \pm 0.3$ & 66 & $35.7 \pm 0.6$ & 95 & $37.2 \pm 1.0$ & 95 & $\mathrm{M}, \mathrm{H}$ \\
\hline 6. South Point SMR & $46.6 \pm 0.4$ & 44 & $44.2 \pm 0.9$ & 89 & $37.4 \pm 0.9$ & 90 & $\mathrm{M}, \mathrm{H}$ \\
\hline \multicolumn{8}{|l|}{ Santa Rosa Island (southeast) } \\
\hline 7. East Point & $27.5 \pm 0.2$ & 48 & $25.5 \pm 0.3$ & 93 & - & - & $\mathrm{L}, \mathrm{M}, \mathrm{H}$ \\
\hline \multicolumn{8}{|l|}{ Santa Cruz Island (southwest) } \\
\hline 8. Gull Island SMR & $49.1 \pm 0.3$ & 35 & $47.5 \pm 0.5$ & 86 & - & - & $\mathrm{M}, \mathrm{H}$ \\
\hline All sites & $38.7 \pm 0.1$ & 55 & $37.1 \pm 0.3$ & 93 & $36.1 \pm 0.4$ & 94 & \\
\hline
\end{tabular}

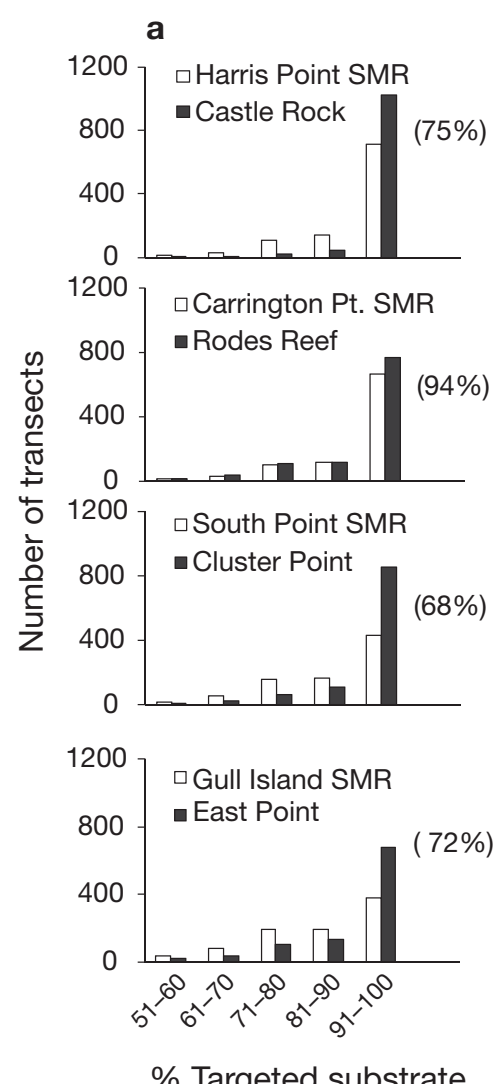

$\%$ Targeted substrate
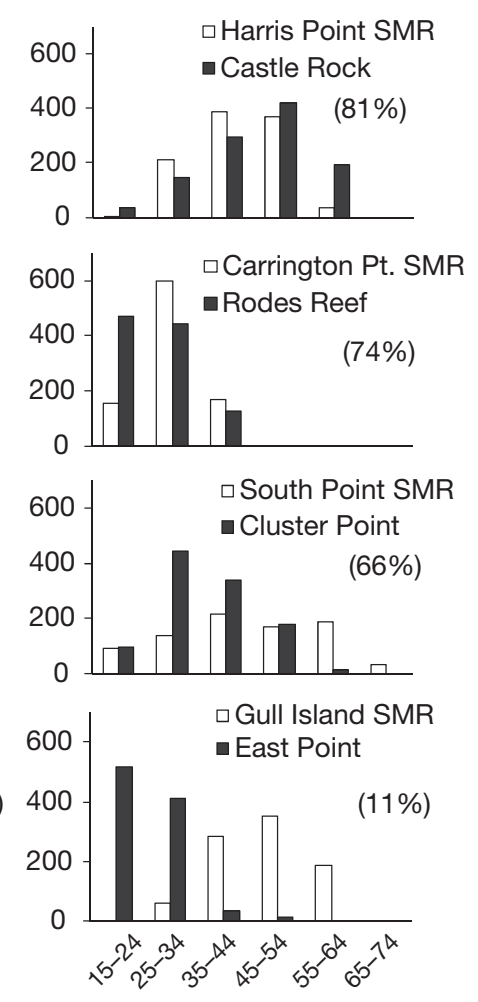

Depth (m)

\section{b}
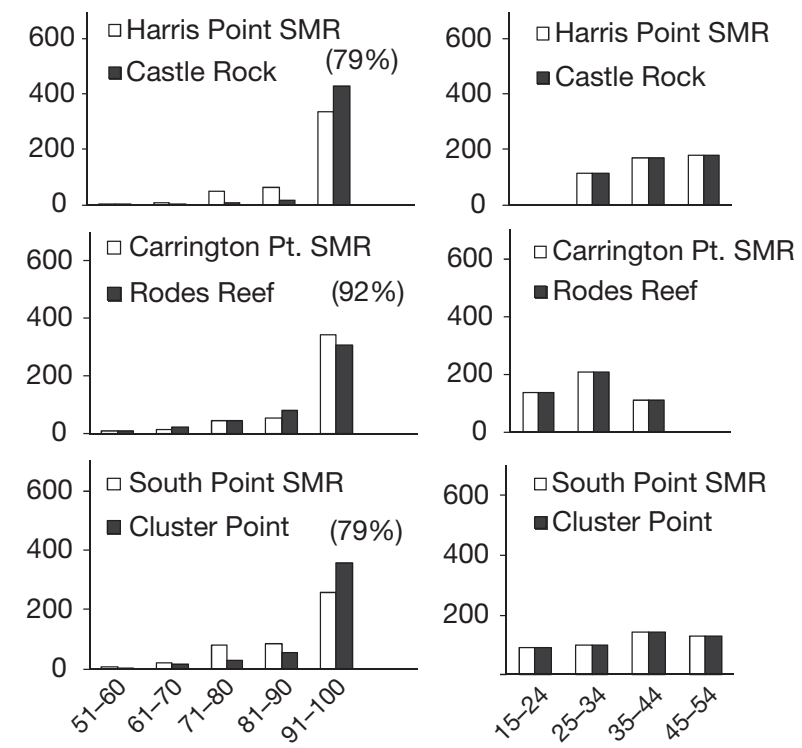

$\%$ Targeted substrate

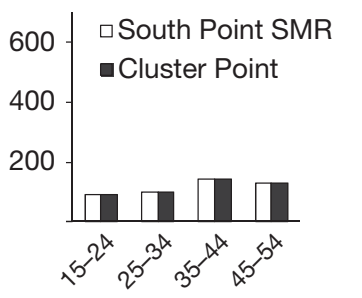

Depth (m)

Fig. 3. Number of transects (years combined) in $10 \%$ bins for targeted substrate and $10 \mathrm{~m}$ bins for depth for the MPA (light bar) and the fished site (dark bar) for each site pair (a) before and (b) after equalizing sampling effort for depth within site pairs. Numbers in parentheses indicate the percent overlap of samples. Because there was insufficient overlap in depth, the Gull Island/East Point site pair was eliminated from the analysis 
After balancing sampling effort by eliminating transects, mean depth (Table 1) and the distribution of sampling effort were equal for the remaining 3 site pairs, as expected because the samples were balanced for depth (Fig. 3b). Overlap for substrate type did not change appreciably, ranging from 79 to $92 \%$ after balancing. Although the distribution of sampling effort by depth was balanced within site pairs, there remained a difference among site pairs (Fig. 3b). For South Point SMR/Cluster Point, transects were sampled from 15 to $54 \mathrm{~m}$. At Harris Point SMR/Castle Rock, there were no transects from 15 to $24 \mathrm{~m}$, and at Carrington Point SMR/Rodes Reef, there were no transects from 45 to $54 \mathrm{~m}$.

In the end there were 115 transects for each site each year, a total of 2760 transects, $46 \%$ of the original total. For the ANOVA there were 1380 transects for treatment, 920 transects for each location and 680 transects for each year.

There was a significant relationship between density and depth (Fig. 4) for 11 of 12 species. There was no significant difference in density across depth zones for pile perch Rhacochilus vacca. Blue rockfish Sebastes mystinus, vermilion rockfish $S$. miniatus, copper rockfish $S$. caurinus and gopher rockfish $S$. carnatus were less abundant in the shallowest zone (15 to $24 \mathrm{~m}$ ) than elsewhere. Blacksmith Chromis punctipinnis, señorita Oxyjulis californica and California sheephead Semicossyphus pulcher were most abundant in the shallowest zones (15 to $34 \mathrm{~m})$. Sebastomus was most abundant in the deepest zone ( 45 to $54 \mathrm{~m}$ ) and olive rockfish Sebastes serranoides, lingcod Ophiodon elongatus and treefish Sebastes serriceps increased in abundance with depth.

The density response ratio was $>0$ for 10 of 12 species; i.e. density was higher in the MPAs than in fished sites (Fig. 5). Blacksmith had the highest ratio (1.9), more than double the ratio for vermilion rockfish. The ratio for the other 9 species ranged from 0.17 to 0.71 . The ratio was approximately zero for olive rockfish. Sebastomus, with a ratio of -0.56 , was the only species more abundant in fished areas than in MPAs. The ratio for all species was 0.64.

The exploration of the data with 3-way ANOVA testing the effect of treatment (MPA vs. fished, location (San Miguel Island, northern Santa Rosa Island and southwestern Santa Rosa Island) and year (2005-2008) showed that most significant interaction terms were associated with location (Table 2, Fig. 6). There was a significant interaction term for year $x$ location and treatment $\times$ location for 10 and 6 (out of 12) species, respectively. The 3-way interaction (treatment $\times$ year $\times$ location) was significant for 7 species. The treatment $\times$ year interaction was significant for only 1 species.
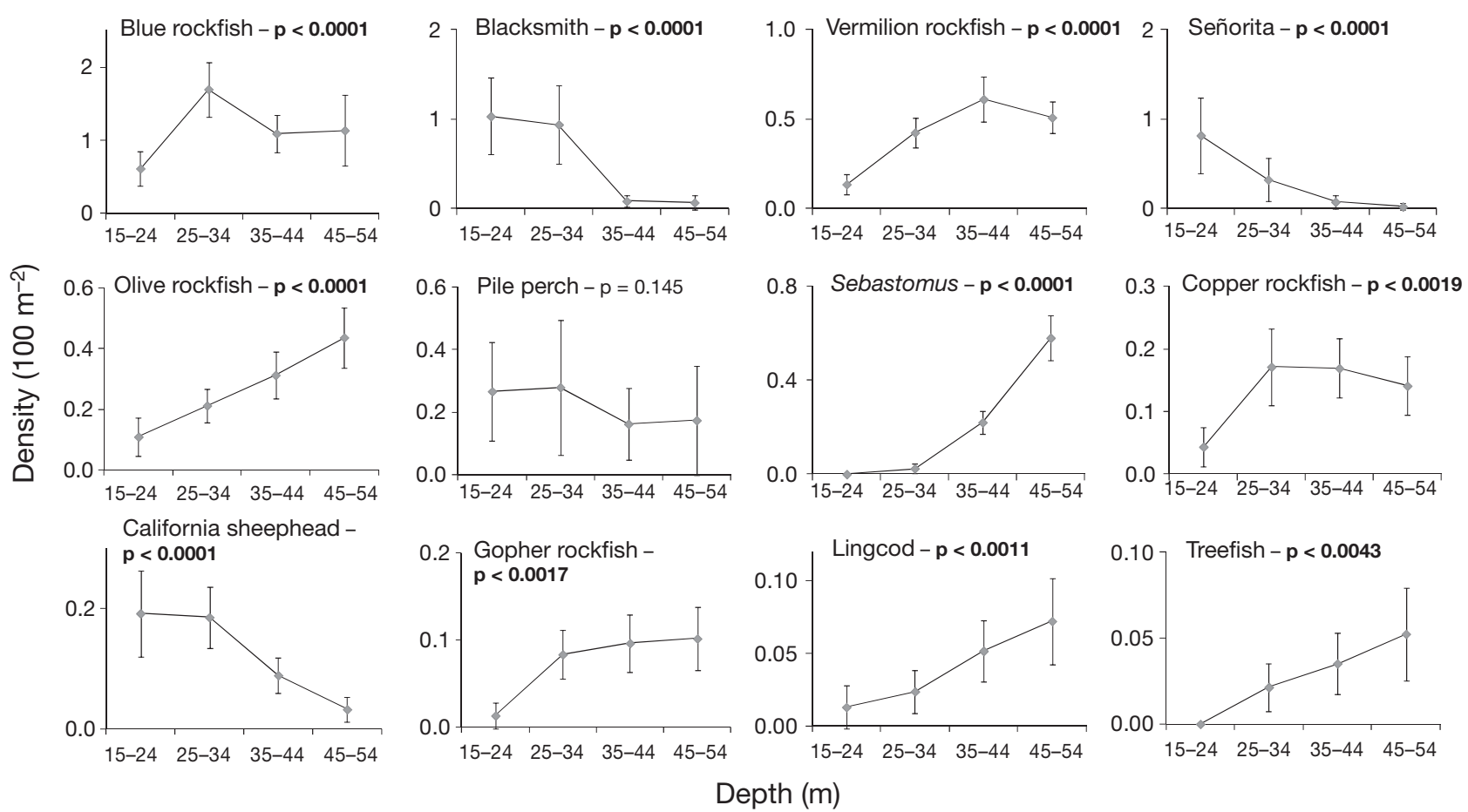

Fig. 4. Mean finfish density within $10 \mathrm{~m}$ depth bins (combined sites and years) for each of the 12 species analysed. Significant $\mathrm{p}$-values (1-way ANOVA) are in bold ( $\mathrm{p} \leq 0.05)$. Error bars are $\pm 95 \%$ confidence intervals 


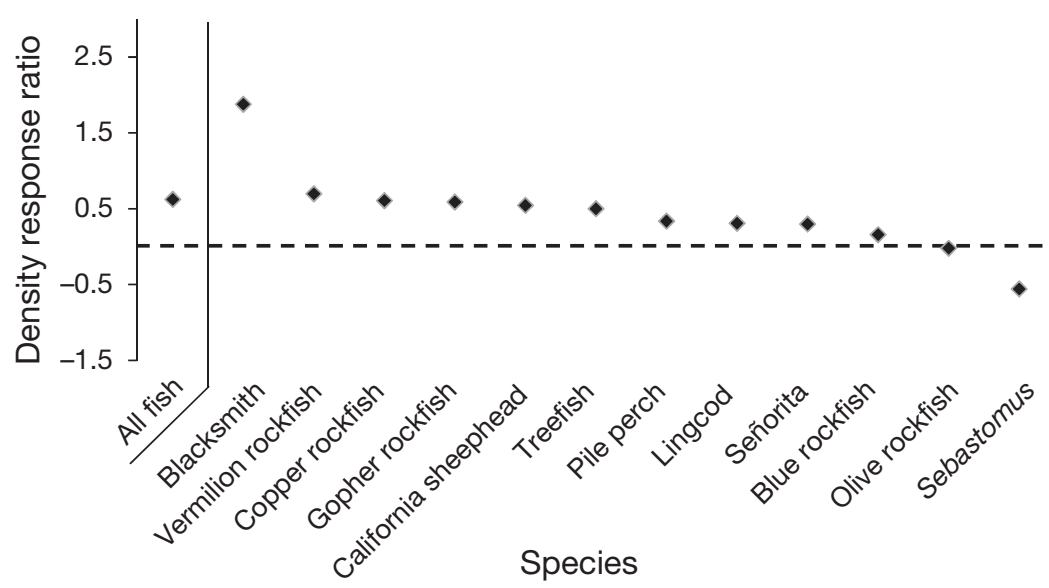

Fig. 5. Density response ratio (ln[MPA density/fished density]), sites and years combined for each finfish species and all species combined. The ratio is $>0$ when density is higher in MPAs

For the species with a significant 3-way interaction, the data were explored for patterns consistent with a treatment effect by testing the difference in density between MPA and fished sites for each year at each location (Table 3, Fig. 6). Two species, pile perch and Sebastomus, showed no evidence of a treatment effect. Where there was a significant difference in density between the MPA and the fished site, the density was higher in the fished site. Blacksmith evidenced the strongest pattern consistent with a treatment effect. Blacksmith was more abundant in the MPA in 3 out of 4 yr on northern Santa Rosa Island and in 2 out of $4 \mathrm{yr}$ at the other locations. Blue rockfish was more abundant in the MPA on southwest Santa Rosa Island in the first $3 \mathrm{yr}$, but more abundant at the fished site in the fourth year. Gopher rockfish was more abun- dant in the MPA on San Miguel Island in the last 3 yr. Señorita and California sheephead were more abundant in the MPA in one location in $2 \mathrm{yr}$.

For the species with a significant treatment $\times$ location interaction, the difference in density between MPAs and fished sites were tested for each of the 3 locations (Fig. 7). Vermilion and copper rockfish were significantly more abundant in the MPA in 2 of 3 locations. Olive rockfish were significantly more abundant in the MPA in one location.

For lingcod, the only species with a significant treatment $\times$ year interaction, density was significantly higher in the MPAs in 2005, but not thereafter (Fig. 8).

\section{DISCUSSION}

The objective of our analysis was to test the null hypothesis that there is no significant difference in density of target species between MPAs and fished sites. Although this may seem a simple task, making reality fit the requirements and assumptions of statistical analysis is anything but simple. In the laboratory, it is relatively easy to control experimental conditions and have a full factorial design with replicated treatments and controls. But under field conditions, particularly with a large geographic area such as with MPAs, conditions on the ground create complications.

Table 2. Probability values for the interaction terms from 3-way ANOVA testing the effect of the factors treatment ( $T$; MPA vs. fished), location (L; San Miguel, north Santa Rosa and southwest Santa Rosa Island) and year (Y; 2005-2008) on density of the 12 most common species. The p-values $\leq 0.05$ are given in bold. All densities were transformed prior to analysis using the method of Pearse \& Hines (1987) (transformed density $=\ln [$ density +1$]$ )

\begin{tabular}{|c|c|c|c|c|c|}
\hline \multirow{2}{*}{ Species } & \multirow{2}{*}{ Common name } & \multicolumn{4}{|c|}{ - Interaction (df) } \\
\hline & & TY (3) & TL (2) & YL (6) & TYL (6) \\
\hline Sebastes mystinus & Blue rockfish & 0.178 & 0.128 & $<0.001$ & $<0.001$ \\
\hline Chromis punctipinnis & Blacksmith & 0.262 & 0.244 & $<0.001$ & $<0.001$ \\
\hline Sebastes miniatus & Vermilion rockfish & 0.164 & $<0.001$ & 0.027 & 0.211 \\
\hline Oxyjulis californica & Señorita & 0.255 & 0.002 & 0.002 & 0.004 \\
\hline Sebastes serranoides & Olive rockfish & 0.243 & 0.048 & $<0.001$ & 0.058 \\
\hline Rhacochilus vacca & Pile perch & 0.326 & 0.260 & 0.033 & 0.004 \\
\hline Sebastomus & Sebastomus & 0.130 & 0.092 & 0.023 & 0.006 \\
\hline Sebastes caurinus & Copper rockfish & 0.353 & $<0.001$ & 0.242 & 0.149 \\
\hline Semicossyphus pulcher & California sheephead & 0.159 & 0.033 & $<0.001$ & 0.002 \\
\hline Sebastes carnatus & Gopher rockfish & 0.298 & 0.003 & 0.085 & $<0.001$ \\
\hline Ophiodon elongatus & Lingcod & 0.022 & 0.225 & 0.020 & 0.079 \\
\hline Sebastes serriceps & Treefish & 0.082 & 0.073 & 0.023 & 0.090 \\
\hline
\end{tabular}



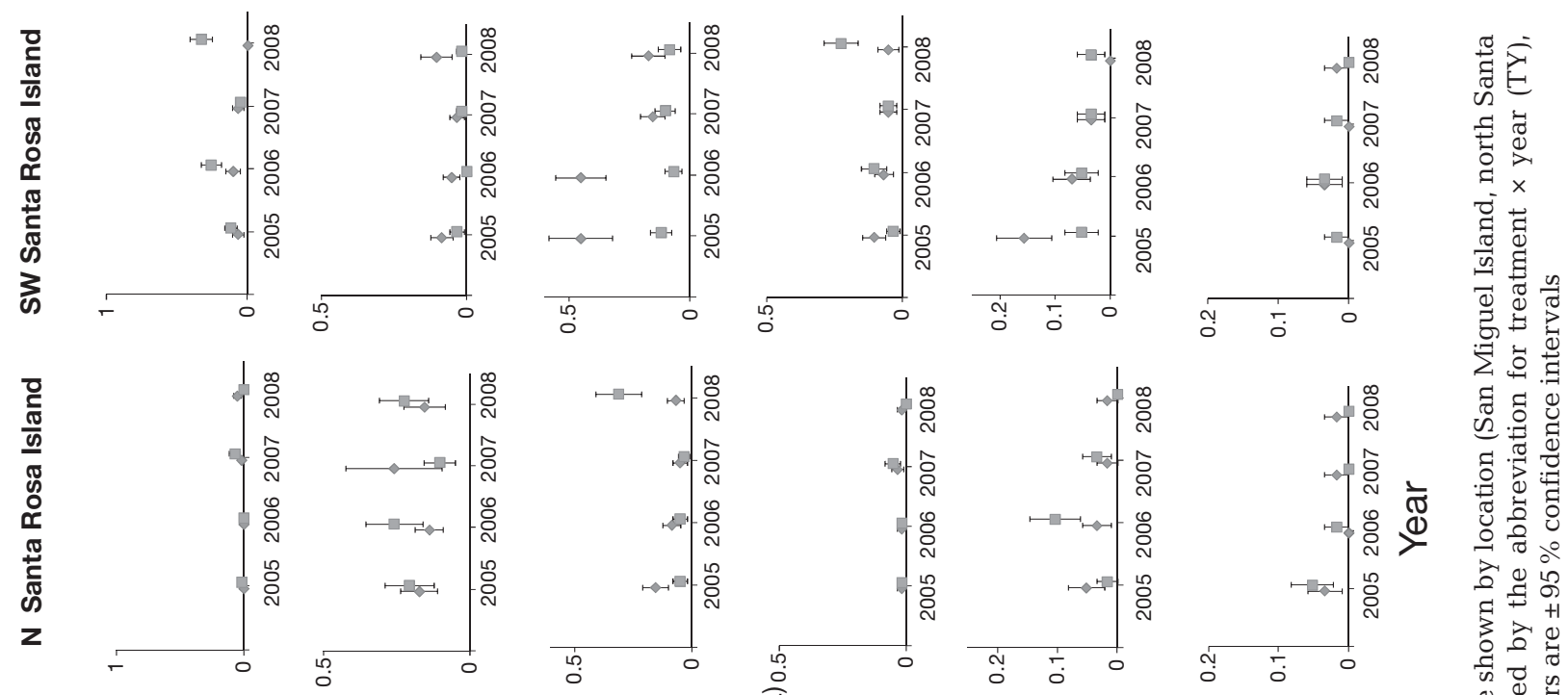

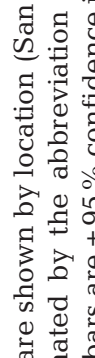
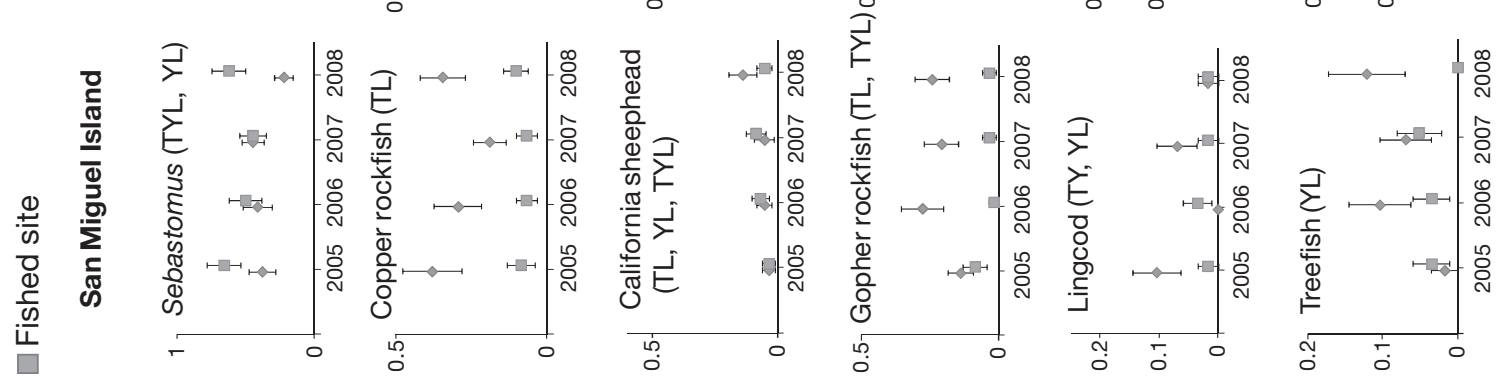

$\sum_{\diamond}^{\mathbb{a}}$
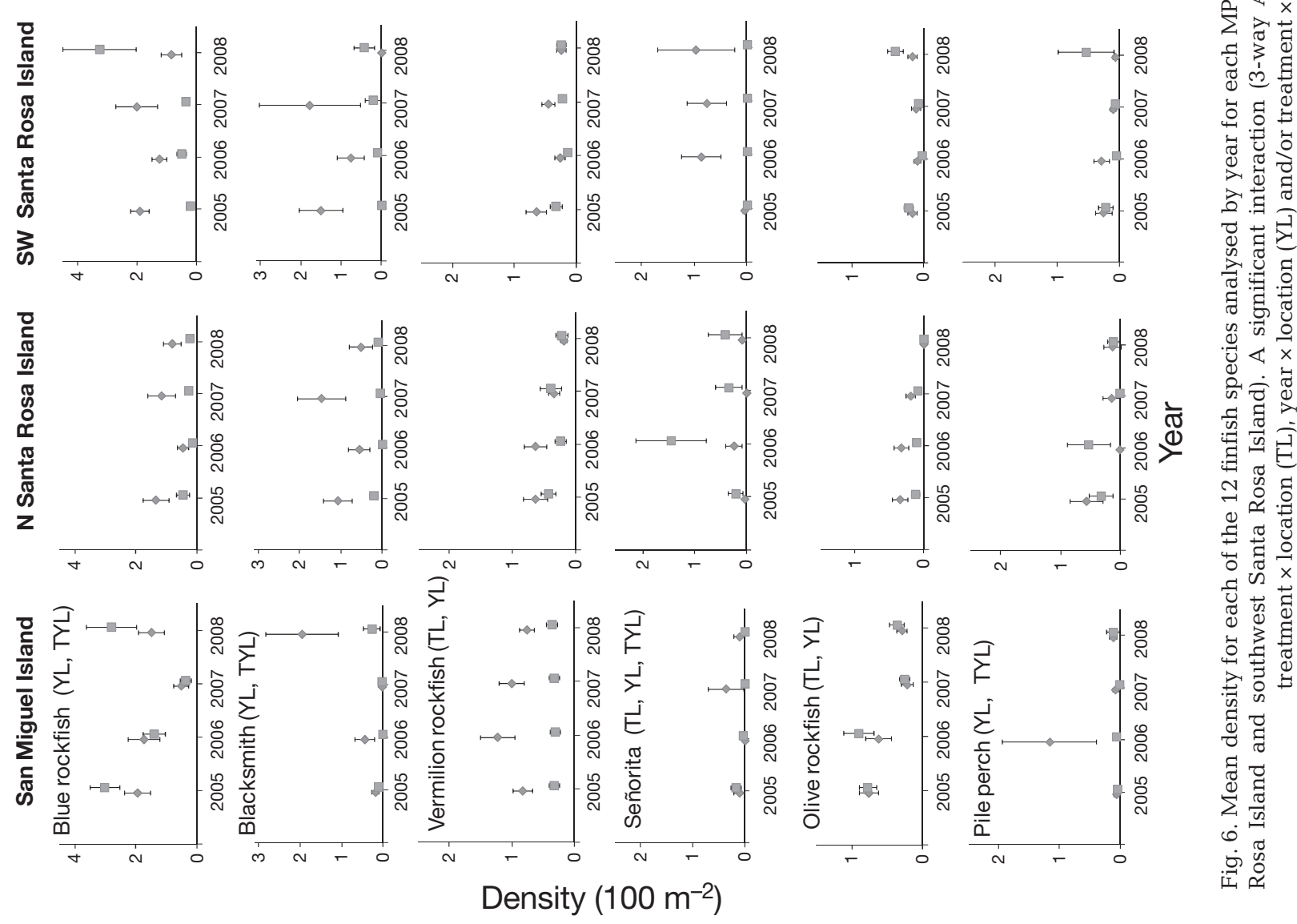

을

웡

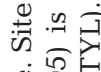

贾造

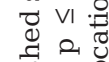

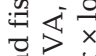

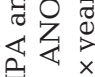

$\sum_{0}^{+}$

ठํ.

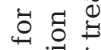

đँ

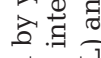

㤩 范

वै है 웡

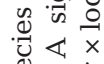

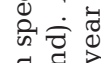

독 면

要

ब․ㅠ

능 च

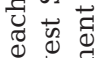


Table 3. Probability values from $t$-tests comparing density in the MPA and fished site for each location each year for the 7 species with a significant interaction for treatment $\times$ location $\times$ year ( 3 -way ANOVA). Probability values in bold when significant $(p \leq 0.05)$. With Bonferroni adjustment, $p=0.0042(\alpha=0.05 / 12)$. A box indicates that the density was significantly higher in the MPA. A dash indicates that no fish were observed

\begin{tabular}{|c|c|c|c|c|c|}
\hline Common name & Location & 2005 & 2006 & 2007 & 2008 \\
\hline Blue rockfish & $\begin{array}{l}\text { San Miguel Island } \\
\text { N Santa Rosa Island } \\
\text { SW Santa Rosa Island }\end{array}$ & \begin{tabular}{|c|}
\multicolumn{1}{c}{0.0288} \\
0.038 \\
$<0.0001$ \\
\end{tabular} & $\begin{array}{l}0.5151 \\
0.2054 \\
\mathbf{0 . 0 0 9 2} \\
\end{array}$ & $\begin{array}{l}0.4617 \\
0.1395 \\
\mathbf{0 . 0 1 8 2} \\
\end{array}$ & $\begin{array}{l}0.2185 \\
0.0883 \\
\mathbf{0 . 0 0 8}\end{array}$ \\
\hline Blacksmith & $\begin{array}{l}\text { San Miguel Island } \\
\text { N Santa Rosa Island } \\
\text { SW Santa Rosa Island }\end{array}$ & \begin{tabular}{|l|}
0.3439 \\
$\mathbf{0 . 0 1 7 9}$ \\
$\mathbf{0 . 0 0 1 8}$ \\
\end{tabular} & \begin{tabular}{|l|}
0.0407 \\
0.0058 \\
0.0353 \\
\end{tabular} & \begin{tabular}{r|}
0.7925 \\
$\mathbf{0 . 0 0 3 1}$ \\
0.0653
\end{tabular} & $\begin{array}{r}\mathbf{0 . 0 4 2 6} \\
0.1823 \\
0.0841\end{array}$ \\
\hline Señorita & $\begin{array}{l}\text { San Miguel Island } \\
\text { N Santa Rosa Island } \\
\text { SW Santa Rosa Island }\end{array}$ & $\begin{array}{l}0.2677 \\
0.3361 \\
0.0833\end{array}$ & \begin{tabular}{r|}
0.1582 \\
$\mathbf{0 . 0 2 7 4}$ \\
$\mathbf{0 . 0 0 2 1}$ \\
\end{tabular} & $\begin{array}{l}0.2155 \\
0.0689 \\
\mathbf{0 . 0 0 7 3} \\
\end{array}$ & $\begin{array}{l}0.3194 \\
0.7498 \\
0.0701\end{array}$ \\
\hline Pile perch & $\begin{array}{l}\text { San Miguel Island } \\
\text { N Santa Rosa Island } \\
\text { SW Santa Rosa Island }\end{array}$ & $\begin{array}{l}0.7097 \\
0.3724 \\
0.8231\end{array}$ & $\begin{array}{l}0.1082 \\
\mathbf{0 . 0 2 6 8} \\
0.0651\end{array}$ & $\begin{array}{l}0.1597 \\
0.3808 \\
0.6408\end{array}$ & $\begin{array}{l}0.5778 \\
0.7623 \\
0.27\end{array}$ \\
\hline Sebastomus & $\begin{array}{l}\text { San Miguel Island } \\
\text { N Santa Rosa Island } \\
\text { SW Santa Rosa Island }\end{array}$ & $\begin{array}{l}0.0548 \\
0.3194 \\
0.2812\end{array}$ & $\begin{array}{c}0.4064 \\
- \\
0.0577\end{array}$ & $\begin{array}{l}0.7868 \\
0.2756 \\
0.8609\end{array}$ & $\begin{array}{r}\mathbf{0 . 0 0 6 4} \\
0.0833 \\
<\mathbf{0 . 0 0 0 1}\end{array}$ \\
\hline $\begin{array}{l}\text { California } \\
\text { sheephead }\end{array}$ & $\begin{array}{l}\text { San Miguel Island } \\
\text { N Santa Rosa Island } \\
\text { SW Santa Rosa Island }\end{array}$ & $\begin{array}{l}1 \\
0.1095 \\
\mathbf{0 . 0 3 5 9} \\
\end{array}$ & $\begin{array}{l}0.7026 \\
0.4739 \\
\mathbf{0 . 0 0 0 6} \\
\end{array}$ & $\begin{array}{l}0.3695 \\
0.6529 \\
0.4253\end{array}$ & $\begin{array}{l}0.1734 \\
\mathbf{0 . 0 1 6 6} \\
0.2605\end{array}$ \\
\hline Gopher rockfish & $\begin{array}{l}\text { San Miguel Island } \\
\text { N Santa Rosa Island } \\
\text { SW Santa Rosa Island }\end{array}$ & $\begin{array}{l}0.319 \\
1 \\
0.1516\end{array}$ & $\begin{array}{l}\mathbf{0 . 0 0 0 6} \\
1 \\
0.6408\end{array}$ & $\begin{array}{l}\mathbf{0 . 0 0 9 8} \\
0.6529 \\
1\end{array}$ & $\begin{array}{l}\mathbf{0 . 0 0 1 9} \\
0.3194 \\
\mathbf{0 . 0 1 0 7}\end{array}$ \\
\hline
\end{tabular}

and all the sites in 2005, 2 yr after implementation of the MPAs.

In a preliminary analysis of our data (California Department of Fish and Game et al. 2008), we used 2-way ANOVA to test the effect of treatment (MPA vs. fished) and time on density. We used data for all 12 target species for all 4 site pairs for 2005-2007. We concluded that there was a significant difference in density between MPAs and fished sites for 8 species. One species, señorita, was more abundant in fished sites.

In this analysis, we wanted to explore the data more fully. In particular we wanted to control for the potentially confounding factors of depth, substrate type and location.

The evaluation of the data for percent target substrate showed substantial overlap in the distribution of sample effort both within and among site

For the ROV sampling program, we anticipated having the resources to sample 10 sites. Conceptually, we wanted to sample a site in each MPA and, for comparison, a nearby fished site. And we wanted to have at least one site pair within each of the 3 major biogeographic zones in the Channel Islands: Oregonian, Transition and Californian (Airamé et al. 2003). Unfortunately, site selection, both within and outside of the MPAs, was seriously constrained because deep-water, hard-bottom substrate is limited and patchy. Approximately $10 \%$ of the bottom between 30 and $100 \mathrm{~m}$ in the Northern Channel Islands is hard substrate (Airamé et al. 2003). Using sonar maps and exploratory ROV surveys, we selected the best available sites, but it was not possible to perfectly control for depth, substrate type and relief, factors known to affect the abundance of fish (Cross \& Allen 1993).

On Anacapa Island it was not possible to establish fished sites because the entire north side of the island was protected.

We were aware of the importance of 'before' data, but delaying implementation was not possible. In addition, it took time to ramp up the ROV sampling program. We were able to sample a few sites in 2004 pairs. For depth, however, because there was only $11 \%$ overlap in the distribution of sample effort, the Gull Island SMR/East Point site pair was eliminated from the analysis. Because there were sufficient samples, we were able to equalize depths for the remaining 3 site pairs by randomly selecting transects. In the end the distribution of sample effort across depth was equal within but not among site pairs.

It is clear from the number of significant interactions that location has a profound effect on the data. This is not surprising given the biogeographic gradient in the islands (Hamilton et al. 2010). There are many factors, including currents, water temperature, wave exposure, predation (e.g. from pinnipeds and sharks), food supply (e.g. from drift kelp) and fishing pressure, that may differ among locations.

The $t$-tests for species with significant treatment $x$ location interactions showed that density was higher in MPAs at 2 locations for vermilion and copper rockfish and at one location for olive rockfish. For both vermilion and copper rockfish, on San Miguel Island there was a pronounced difference in density between the MPA and fished site in all years. On southwest Santa Rosa Island, density was lower in both the MPA and the fished site, and the difference was less 


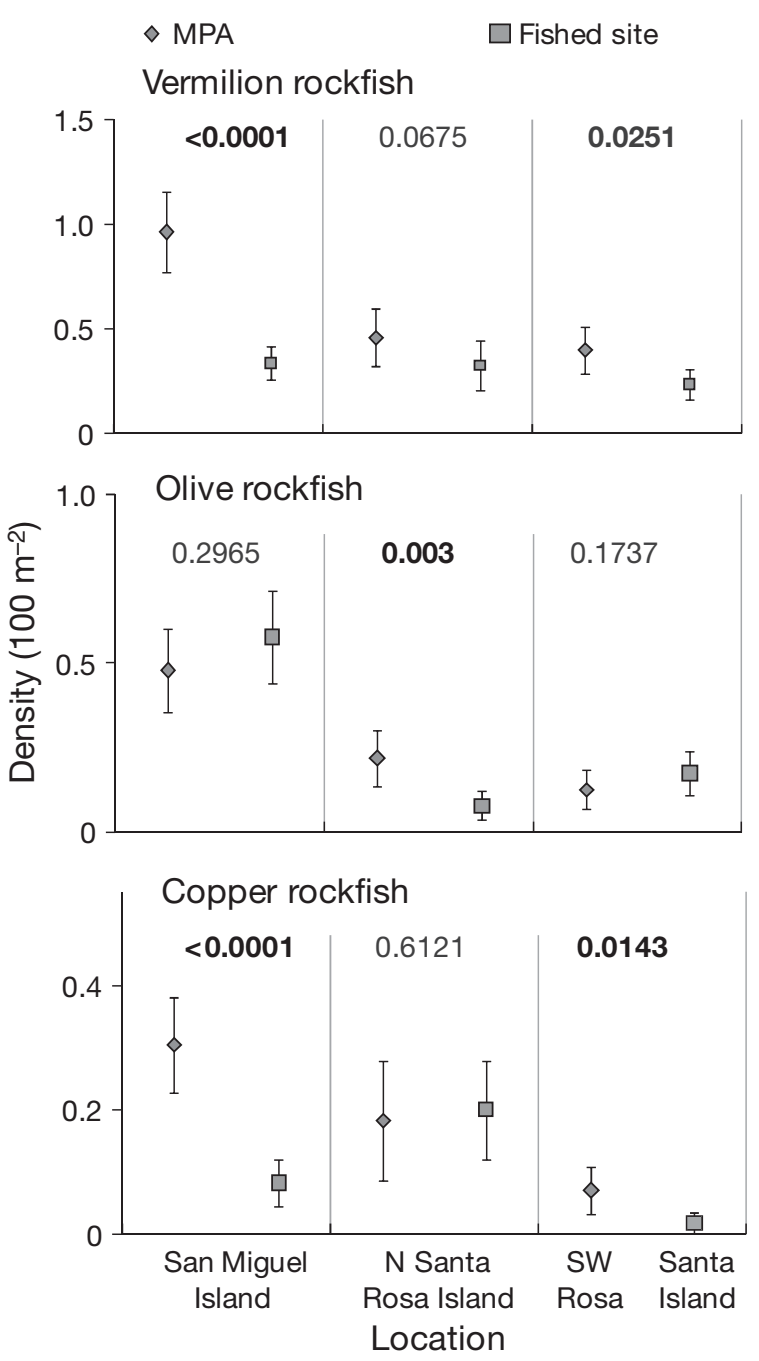

Fig. 7. Mean finfish density at each MPA and fished site at each location (years combined) for the 3 species with a significant treatment $\times$ location (TL) interaction (3-way ANOVA). Significant $\mathrm{p}$-values from $t$-tests are in bold ( $\mathrm{p} \leq$ 0.05). With the Bonferroni adjustment, $p=0.0167(\alpha=$ $0.05 / 3)$. Error bars are $\pm 95 \%$ confidence intervals

pronounced. For olive rockfish on northern Santa Rosa Island, the difference in density between the MPA and the fished site was more pronounced in the first $2 \mathrm{yr}$ than in the last $2 \mathrm{yr}$.

There was a significant interaction between treatment and year for only one species (lingcod). The density of lingcod was significantly higher in MPAs than at fished sites in 2005, but not thereafter. Because density decreased over time in the MPAs relative to the fished sites, the response was most likely not associated with protection.

Among the species with significant interactions for treatment $\times$ location $\times$ year, blacksmith and blue rockfish had the most positive tests. Blacksmith also

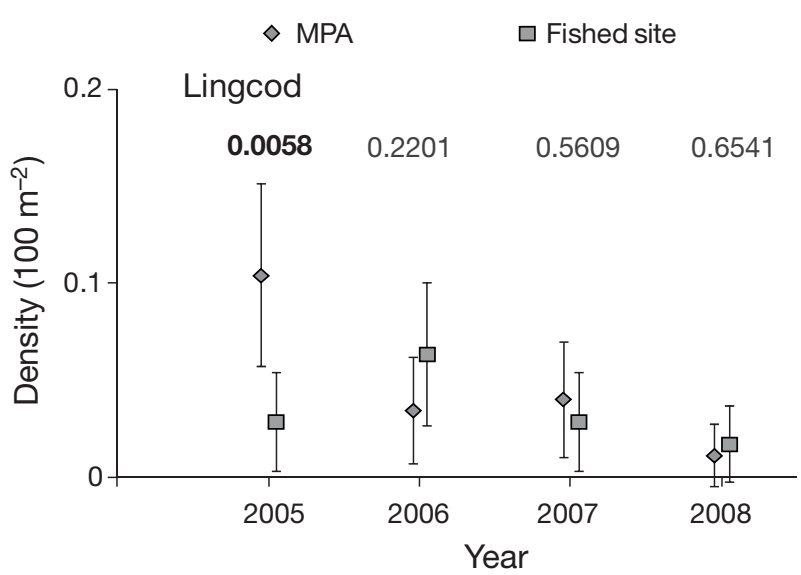

Fig. 8. Mean finfish density at each MPA and fished site each year (locations combined) for lingcod, the one species with a significant treatment $\times$ year $(\mathrm{TY})$ interaction (3-way ANOVA). Significant $\mathrm{p}$-values from $t$-tests are in bold $(\mathrm{p} \leq 0.05)$. With the Bonferroni adjustment, $\mathrm{p}=0.0126(\alpha=$ $0.05 / 4)$. Error bars are $\pm 95 \%$ confidence intervales

had the highest density response ratio, more than double the ratio for any other species. However, the temporal pattern of the tests did not conform well to the expectation that density should increase over time in the MPAs. For blacksmith, in 2 locations there was no significant difference in density in the last year of sampling, and in the third location the difference was significant only in the second and fourth years. For blue rockfish, on northern Santa Rosa Island the difference in density was significant only in the first year. On southwestern Santa Rosa Island, density was higher in the MPA in the first $3 \mathrm{yr}$, but significantly higher at the fished site in the fourth year. The only species showing a pattern of response consistent with the expectation of increasing density was gopher rockfish on San Miguel Island. There were no significant differences in density of gopher rockfish on northern Santa Rosa Island, and the density was higher at the fished site in one year on southwest Santa Rosa Island.

Of all the species, gopher rockfish and vermilion rockfish on San Miguel Island and copper rockfish on San Miguel and southwest Santa Rosa Islands conformed most to the expectation that density either should be consistently higher or increase in the MPAs. Clearly, no species was consistently more abundant in MPAs than at fished sites for all locations, a conclusion that seems inconsistent with the results of the preliminary analysis, which showed a significant difference in density for 8 of the 12 species, with one species (señorita) more abundant at fished sites. 
The analyses differ in that there was one more year of data in the present study than in the preliminary analysis, and the Gull Island/East Point site pair was eliminated because sampling depths were mismatched. Based on the density response ratios, taking out one site pair affected the results more than adding an additional year of data (Table 4). When density response ratios calculated with 4 site pairs and data for 2005-2007 were compared with ratios calculated with the addition of the 2008 data, the average difference was 0.09 . The average difference for 3 and 4 site pairs for the 2005-2008 data was 0.43 . Taking out the site pair not only changed the magnitude of the density response ratio, but also affected the sign of the ratio: the value changed from negative to positive for señorita and from positive to negative for olive rockfish and Sebastomus. It is somewhat surprising that with the exclusion of the Gull Island/East Point site pair the ratio for all species did not change very much, ranging from 0.56 to $0.63,1.7$ to 1.9 times the density in fished areas. The ratio for all species is similar to the value reported in Halpern (2003).

The preliminary analysis did not control for location, but clearly location profoundly affected the results. In this analysis, we used significant interaction terms to indicate the possibility of treatment effects and then decomposed the variance depending on the type of interaction. Exploring the data in more detail exposed the variability in response between site pairs as well as the response over time within site pairs.

It is apparent that there are inherent difficulties with using ANOVA to measure the effect of MPAs in a large geographic area. Another approach is to use a sampling design with multiple stations and data on controlling variables to elucidate differences between sites. With sufficient financial resources, it is possible to collect data on temperature, wave action and currents, among other things. But some crucial data may not be available. For instance, in our case, the data on fishing pressure were collected at a geographic scale that is too large to allow for analysis for differences among sites. And sometimes there is an unavoidable problem with confounding factors. For instance, because fishing pressure is known to vary with distance to the nearest port (Karpov et al. 2000), it is likely that fishing pressure decreases from east to west, from Anacapa Island to San Miguel Island. Because water temperature also decreases from east to west, fishing pressure and temperature are confounded.

Certainly having 'before' data would help differentiate pre-existing differences from MPA effects. But, in our experience, it is difficult, if not impossible, to delay implementation of protection to allow the scientists to collect 'before' data. In all probability, most studies will not be able to use a before/after/control/ impact (BACI) design (Stewart-Oaten et al. 1986).

Temporal analysis may provide evidence of an MPA effect. If density in the MPA increases over time in relation to a nearby fished site and the change is associated in time with implementation of the MPA, then it seems reasonable to conclude that the change is due to protection. It is possible that confounding factors may influence one site and not the other, but generally most controlling factors such as wave

Table 4. Density response ratios (ln[MPA density/fished density]) for each species using: (A) 3 site pairs from 2005 to 2008 balanced for depth; (B) 4 site pairs from 2005 to 2008, not balanced; and (C) 4 site pairs from 2005 to 2007, not balanced. Values $<0$ are bolded to highlight species more abundant at fished sites

\begin{tabular}{|c|c|c|c|c|c|c|}
\hline \multirow{2}{*}{ Common name } & \multirow{2}{*}{$\begin{array}{c}\text { A } \\
2005-2008\end{array}$} & \multirow{2}{*}{$\begin{array}{c}\text { B } \\
2005-2008\end{array}$} & \multirow{2}{*}{$\frac{C}{2005-2007}$} & \multicolumn{3}{|c|}{ Difference (absolute value) } \\
\hline & & & & & A-B & $\mathrm{B}-\mathrm{C}$ \\
\hline Blacksmith & 1.89 & 0.70 & 0.57 & & 1.18 & 0.13 \\
\hline Vermilion rockfish & 0.71 & 0.98 & 1.04 & & 0.27 & 0.06 \\
\hline Copper rockfish & 0.62 & 0.73 & 0.88 & & 0.11 & 0.15 \\
\hline Gopher rockfish & 0.60 & 0.93 & 0.89 & & 0.33 & 0.04 \\
\hline California sheephead & 0.55 & 0.35 & 0.39 & & 0.21 & 0.04 \\
\hline Treefish & 0.51 & 0.85 & 0.71 & & 0.34 & 0.13 \\
\hline Pile perch & 0.35 & 0.49 & 0.71 & & 0.14 & 0.22 \\
\hline Lingcod & 0.32 & 0.53 & 0.50 & & 0.21 & 0.03 \\
\hline Señorita & 0.31 & -0.71 & -0.72 & & 1.02 & 0.01 \\
\hline Blue rockfish & 0.17 & 0.55 & 0.67 & & 0.38 & 0.12 \\
\hline Olive rockfish & -0.01 & 0.14 & 0.24 & & 0.15 & 0.10 \\
\hline Sebastomus & -0.55 & 0.28 & 0.33 & & 0.82 & 0.05 \\
\hline \multirow[t]{2}{*}{ All species } & 0.63 & 0.56 & 0.59 & & & \\
\hline & & & & Average & 0.43 & 0.09 \\
\hline
\end{tabular}


action and water temperature operate on fairly large scales (Hamilton et al. 2010). In our case, the only species with a significant treatment $\times$ year interaction was lingcod; however, density was higher in the MPAs in 2005, but not thereafter. Because successful recruitment for most of our species is driven by optimal oceanic conditions that often occur many years apart (Hollowed et al. 1987, Karpov et al. 1995, Selkoe et al. 2007, Caselle et al. 2010) and the species are mostly slow growing with long life spans (Miller \& Geibel 1973, Love et al. 2002), we did not expect to see a quick response to protection.

In the Channels Islands in 2003, there was good settlement of some rockfish species, including olive rockfish, gopher rockfish and copper rockfish, followed by recruitment failure from 2004 to 2008 (Caselle et al. 2010). Most of our rockfish species and California sheephead are sufficiently large within $1 \mathrm{yr}$ of settlement to be included in our sampling (Lea et al. 1999, Alonzo et al. 2008). Therefore, any fish that settled after implementation of the MPAs in 2003 would have been counted in 2005 and 2006. There is no size limit on rockfishes for either recreational or commercial fishing in California, so fish that recruited in 2003 could be caught. Presumably if there were a major recruitment event combined with differential mortality, there would be significant treatment $\times$ year interactions, but this was not the case. It may be that the 2003 recruitment event was either too small and/or subsequent mortality too high to change population size.

Increases in density in MPAs within a few years of protection have been reported by many authors (Halpern \& Warner 2002, Claudet et al. 2006, Hamilton et al. 2010). However, to date, there is little information about the trajectory of change or mechanisms involved in a rapid response to protection. It would be informative to have sufficient sampling before MPAs are established and in the first couple of years after establishment to measure trajectories and elucidate processes such as immigration and mortality of adult fish and settlement of young of the year.

It is important to remember that we are measuring the initial stages in the development of the Channel Islands MPAs. Because there are no historical data, we do not know the carrying capacity of MPAs in the northern Channel Islands; however, given time for growth and recruitment, we expect the density of fish in the MPAs to change. MPA effects can be identified with significant treatment $\times$ year interactions. With additional time, the full dimensions of protection should become evident.
Acknowledgements. This work represents the cooperative effort of many staff from both the California Department of Fish and Game (CDFG) and the Pacific States Marine Fisheries Commission who together worked hard to make this program a success. The field work could not have been completed without the vessel support on the RV 'Shearwater' provided by the Channel Islands National Marine Sanctuary program of the National Oceanic and Atmospheric Administration. CDFG funding for this project was augmented by grants from the Sportfish Restoration Act, the Ocean Protection Council, the California State Coastal Conservancy, The Nature Conservancy, Marine Applied Research and Exploration, the Marisla Foundation and Kingfisher. Thanks are due to Rikk Kvitek of California State University at Monterey Bay, and Guy Cochrane of the United States Geological Survey, for providing seafloor mapping. Special thanks are due to the following CDFG staff: Philip Law for statistical advice; Mary Patyten for editing assistance with the manuscript; and Chuck Valle for insightful guidance on how best to present this science to the reader.

\section{LITERATURE CITED}

Abesamis RA, Russ GR (2005) Density-dependent spillover from a marine reserve: long-term evidence. Ecol Appl 15: 1798-1812

Airamé S, Dugan JE, Lafferty KD, Leslie H, McArdle DA, Warner RR (2003) Applying ecological criteria to marine reserve design: a case study from the California Channel Islands. Ecol Appl 13:170-184

Alonzo SH, Ish T, Key M, MacCall AD, Mangel M (2008) The importance of incorporating protogynous sex change into stock assessments. Bull Mar Sci 83:163-179

Barry JP, Baxter C (1993) Survey design considerations for deep-sea benthic communities using ROVs. Mar Technol Soc J 26:20-26

California Department of Fish and Game, Partnership for Interdisciplinary Studies of Coastal Oceans, Channel Islands National Marine Sanctuary, Channel Islands National Park (2008) Channel Islands marine protected areas: first 5 years of monitoring: 2003-2008. Available at www.dfg.ca.gov/marine/channel_islands/fiveyears.asp

Caselle JE, Wilson JR, Carr MH, Malone DP, Wendt DE (2010) Can we predict interannual and regional variation in delivery of pelagic juveniles to nearshore populations of rockfishes (genus Sebastes) using simple proxies of ocean conditions? CCOFI Rep 51:91-105

Claudet J, Pelletier D, Jouvenel JY, Bachet F, Galzin R (2006) Assessing the effects of marine protected area (MPA) on a reef fish assemblage in a northwestern Mediterranean marine reserve: identifying communitybased indicators. Biol Conserv 130:349-369

Cross JN, Allen LG (1993) Fishes. In: Dailey MD, Reish DJ, Anderson JW (eds) Ecology of the Southern California Bight. University of California Press, Berkeley, CA, p 459-540

Edgar GJ, Barrett NS (1997) Short term monitoring of biotic change in Tasmanian marine reserves. J Exp Mar Biol Ecol 213:261-279

> Greene HG, Yoklavich MM, Starr RM, O'Connell VM and others (1999) A classification scheme for deep sea habitats. Oceanol Acta 22:663-678

Halpern BS (2003) The impact of marine reserves: do reserves work and does reserve size matter? Ecol Appl 
13(Suppl):117-137

Halpern BS, Warner RR (2002) Marine reserves have rapid and lasting effects. Ecol Lett 5:361-366

Hamilton SL, Caselle JE, Malone DP, Carr MH (2010) Incorporating biogeography into evaluations of the Channel Islands marine reserve network. Proc Natl Acad Sci USA 107:18272-18277

Hedges LV, Gurevitch J, Curtis PS (1999) The meta-analysis of response ratios in experimental ecology. Ecology 80: 1150-1156

Hollowed AB, Bailey KM, Wooster WS (1987) Patterns in recruitment of marine fishes in the northeastern Pacific Ocean. Biol Oceanogr 5:99-131

Huntington BE, Karnauskas M, Babcock EA, Lirman D (2010) Untangling natural seascape variation from marine reserve effects using a landscape approach. PLoS ONE 5:e12327

Karpov KA, Albin DP, Van Buskirk WH (1995) The marine recreational fishery in northern and central California a historical comparison (1958-86), status of stocks (1980-86), and effects of changes in the California Current. Fish Bull Calif Fish Game 176:1-192

Karpov KA, Haaker PL, Taniguchi IK, Rogers-Bennett L (2000) Serial depletion and the collapse of the California abalone (Haliotis spp.) fishery. In: Campbell EA (ed) Workshop on Rebuilding Abalone Stocks in British Columbia, Can Spec Publ J Fish Aquat Sci 130: 11-24

Karpov KA, Lauermann A, Bergen M, Prall M (2006) Accuracy and precision of measurements of transect length and width made with a remotely operated vehicle. Mar Technol Soc J 40:79-85

Karpov KA, Bergen M, Geibel JJ, Valle CF, Fox D (2010) Prospective (a priori) power analysis for detecting changes in density when sampling with strip transects. Calif Fish Game 96:69-81

Lea RN, McAllister RD, VenTresca DA (1999) Biological aspects of nearshore rockfishes of the genus Sebastes from central California with notes on ecologically related sport fishes. Fish Bull Calif Fish Game 177:4-112

Lester SE, Halpern BS, Grorud-Colvert K, Lubchencho J and others (2009) Biological effects within no-take marine reserves: a global synthesis. Mar Ecol Prog Ser 384:33-46

Editorial responsibility: Lisandro Benedetti-Cecchi, Pisa, Italy
Love MS, Yoklavich M, Thorsteinson L, Butler J (2002) The rockfishes of the northeast Pacific. University of California Press, Berkeley, CA

- Love MS, Yoklavich M, Schroeder DM (2009) Demersal fish assemblages in the Southern California Bight based on visual surveys in deep water. Environ Biol Fishes 84: $55-68$

Mason RL, Gunst RF, Hess JL (1989) Statistical design and analysis of experiments. John Wiley \& Sons, New York, NY

Miller DJ, Geibel JJ (1973) Summary of blue rockfish and lingcod life histories; a reef ecology study; and giant kelp, Macrocystis pyrifera, experiments in Monterey Bay, California. Fish Bull Calif Fish Game 158:1-137

Parry DM, Kendall MA, Pilgrim DA, Jones MB (2003) Identification of patch structure within marine benthic landscapes using remotely operated vehicle. J Exp Mar Biol Ecol 285-286:497-511

Pearse JS, Hines AH (1987) Long-term population dynamics of sea urchins in a central California kelp forest: rare recruitment and rapid decline. Mar Ecol Prog Ser 39: 275-283

Selkoe KA, Vogel A, Gaines SD (2007) Effects of ephemeral circulation on recruitment and connectivity of nearshore fish populations spanning Southern and Baja California. Mar Ecol Prog Ser 351:209-220

> Stewart-Oaten A, Murdoch WW, Parker KE (1986) Environmental impact assessment: 'pseudoreplication' in time? Ecology 67:929-940

> Tetreault I, Ambrose RF (2007) Temperate marine reserves enhance targeted but not untargeted fishes in multiple no-take MPAs. Ecol Appl 17:2251-2267

> Trenkel VM, Francis RICC, Lorance P, Mahévas S, Rochet MJ, Tracey DM (2004) Availability of deep-water fish to trawling and visual observation from a remotely operated vehicle (ROV). Mar Ecol Prog Ser 284:293-303

Underwood AJ (1997) Experiments in ecology: their logical design and interpretation using analysis of variance. Cambridge University Press, Cambridge

Yoklavich MM, Greene JG, Cailliet GM, Sullivan DE, Lea RN, Love MS (2000) Habitat associations of deep-water rockfishes in a submarine canyon: an example of a natural refuge. Fish Bull US 98:625-641

Submitted: January 24, 2011; Accepted: January 30, 2012 Proofs received from author(s): April 25, 2012 